\title{
Applied Uses of Extracorporeal Membrane Oxygenation Therapy
}

\author{
Avani R. Patel ${ }^{1}$, Amar R. Patel ${ }^{1}$, Shivank Singh ${ }^{2}$, Shantanu Singh ${ }^{3}$, Imran Khawaja ${ }^{3}$ \\ 1. Internal Medicine, Northern California Kaiser Permanente, Fremont, USA 2. Internal Medicine, Southern Medical \\ University, Guangzhou, CHN 3. Pulmonary Medicine, Marshall University School of Medicine, Huntington, USA
}

Corresponding author: Avani R. Patel, avani.94539@gmail.com

\begin{abstract}
Extracorporeal membrane oxygenation (ECMO) therapy has been around since the 1970s and has completely changed how critical care physicians view supportive therapy for certain patients. ECMO therapy is a supportive therapy provided by a mechanical extracorporeal circuit that is able to directly oxygenate and remove carbon dioxide from the blood. By performing this, ECMO can provide cardiac, respiratory, or combined cardiopulmonary supportive therapy in cases of failure. ECMO therapy also places less emphasis on invasive mechanical ventilation, which prevents barotrauma and gives rest to the lungs. Therefore, they are used for several different conditions. This review article focuses on the definition, principles, types, and practical applications of ECMO therapy.
\end{abstract}

Received 06/24/2019

Review began 06/26/2019 Review ended 07/16/2019 Published 07/17/2019

๑) Copyright 2019 Patel et al. This is an open access article distributed under the terms of the Creative Commons Attribution License CC-BY 3.0., which permits unrestricted use, distribution, and reproduction in any medium, provided the original author and source are credited.
Categories: Cardiac/Thoracic/Vascular Surgery, Internal Medicine, Pulmonology

Keywords: extracorporeal membrane oxygenation (ecmo), venoarterial extracorporeal membrane oxygenation (vaecmo), cardiogenic shock, respiratory failure, sepsis-induced cardiomyopathy, venovenous extracorporeal membrane oxygenation (vv-ecmo), pulmonary embolism, cardiopulmonary resuscitation (cpr), femoral vein, lung rest

\section{Introduction And Background}

Extracorporeal membrane oxygenation (ECMO) therapy has changed the way physicians view supportive treatment for cardiac, respiratory, or combined cardiopulmonary failure. ECMO therapy provides days to weeks of supportive treatment to patients with cardiac, respiratory, and combined cardiopulmonary failure [1]. ECMO was first reported in 1974 [1, 2]. From 2006 to 2011, the use of ECMO in adult patients has increased by more than $433 \%$ within the United States alone [1,2]. The typical ECMO circuit consists of a blood pump, the membrane oxygenator (acts as an artificial lung), conduit tubing, a heat exchanger, as well as a drainage cannula and a return cannula [1]. It is a process that involves an extracorporeal circuit that directly oxygenates and removes carbon dioxide from the blood using an oxygenator. An oxygenator is a gas exchange device that uses a semipermeable membrane in order to separate a blood compartment from a gas compartment. The ECMO therapy process consists of deoxygenated blood withdrawn through a drainage cannula by an external pump, which then passes through the oxygenator, and is finally returned to the patient through a reinfusion cannula [3]. Briefly, the ECMO circuit drains blood from the venous system and after pumping it through the membrane oxygenator, the newly oxygenated blood is returned to the patient. By doing this, ECMO allows for a reduction of ventilator settings to decrease the chances of lung injury [1]. ECMO provides "lung rest," by allowing lower tidal volumes and pressures. Therefore as proven in earlier studies, ECMO should be associated with a lower mortality rate because it allows for lower fractions of inspired oxygen to be used in mechanical ventilation [4]. Despite this, the data are still contradicting regarding the lower mortality rate in ECMO. The most recent randomized trial for ECMO in severe acute respiratory distress syndrome (ARDS) (ECMO to Rescue Lung Injury in Severe ARDS [EOLIA]) failed to show mortality benefit from using early ECMO despite benefit in secondary outcomes and possibly mortality when accounting for cross-over [5]. Also, if a mortality benefit is present, lower fractional concentrations of $\mathrm{O}_{2}$ in inspired gas $\left(\mathrm{FiO}_{2}\right)$ may be one of the contributing factors but a cause-effect relationship with mortality is not certain. Nonetheless, ECMO therapy is highly utilized [5]. This review article examines the different applications of ECMO therapy in the intensive care unit setting. Our aim is to highlight the data that are present and bring notice to where data are lacking and could potentially benefit from further academic studies. Our aim is to highlight the present data and their limitations, as well as how these data could potentially benefit from further academic studies.

\section{Review}

\section{Different modes of ECMO therapy}

ECMO therapy subdivided into venovenous extracorporeal membrane oxygenation (VV-ECMO) and venoarterial extracorporeal membrane oxygenation (VA-ECMO).

VV-ECMO is a process where the blood is drained from a central vein and returned to another central vein with the device only providing gas exchange [4]. By utilizing this bridging therapy, oxygen support is provided while the lungs recover in respiratory failure [3]. VV-ECMO involves venous cannulation at two 
different sites for drainage and reinfusion of the blood [6]. A VV-ECMO normally has two access sites so it requires one femoral venous access for drainage and one femoral venous access for reinfusion. With the addition of the bicaval dual-lumen cannula, the internal jugular vein can be used as a lone access site for VVECMO $[3,7-8]$.

VA-ECMO is a process where the blood is drained from the venous system and pumped into an artery with the circuit providing both respiratory and circulatory support [4]. This is done for patients who have compromised cardiac function with or without impaired gas exchange. The VA-ECMO circuit typically consists of femoral vein drainage and reinfusion through the femoral artery [3].

\section{Uses in cardiac failure}

Cardiogenic Shock for Non-myocardial Infarction Etiologies

The definition of cardiogenic shock is a primary cardiac disorder that results in both clinical and biochemical evidence of tissue hypoperfusion. Cardiogenic shock is clinically diagnosed by a systolic blood pressure (BP) of $\leqslant 90 \mathrm{~mm} \mathrm{Hg}$ either with or without support, for 30 or more minutes, and a urine output $\leqslant 30$ $\mathrm{mL} /$ hour or cool extremities [9]. Cardiogenic shock hemodynamic criteria will have a decreased cardiac index $\left(\leqslant 2.2 \mathrm{~L} / \mathrm{min} / \mathrm{m}^{2}\right.$ body surface area) and an increased pulmonary-capillary wedge pressure (> $15 \mathrm{~mm} \mathrm{Hg}$ ) [9].

One application of ECMO is supportive treatment for non-ischemic cardiogenic shock, including cardiogenic shock caused by fulminant myocarditis [10-12]. The World Health Organization and the International Society and Federation of Cardiology defined myocarditis as an inflammatory disease of the myocardium, which is diagnosed by established histological, immunological, and immunohistochemical criteria [13]. As seen with previous prospective studies, fulminant myocarditis that is treated with percutaneous ECMO has been proven to have a good clinical outcome that is comparable to outcomes seen in patients of nonfulminant myocarditis [10].

Cardiogenic Shock Complicating Acute Myocardial Infarction

Cardiogenic shock secondary to acute myocardial infarction is also treated with VA-ECMO therapy. It offers an advantage over traditional medical therapy (inotropes and vasopressors) in that cardiac output is increased without putting an increased demand on myocardial tissue. It also offers the benefit of rapid insertion, biventricular support, and lung rest in cases of simultaneous respiratory failure [3]. Early ECMO therapy initiation in patients with cardiogenic shock secondary to myocardial infarction has demonstrated improved 30-day outcomes in patients [14]. In a different study performed two years later, it was confirmed that patients benefited with improved 30-day outcomes and that their one-year outcome was also better with the ECMO therapy [15].

Sepsis-associated Cardiomyopathy

Septic shock can lead to cardiac and hemodynamic failure. In those cases, VA-ECMO can be used as supportive therapy. Previous studies have determined that pediatric patients with refractory septic shock have been associated with good clinical outcomes after VA-ECMO but there is a lack of consensus for adult patients [16]. Some studies have determined that adult patients of septic shock improve greatly after VAECMO therapy [16-17]. One retrospective, single-center, observational study and a cross-sectional survey determined that VA-ECMO therapy rescued more than $70 \%$ of patients who developed refractory cardiovascular dysfunction secondary to severe bacterial septic shock with survivors also reporting good long-term quality of life [16]. Another prospective study found that the results of VAECMO therapy in septic shock patients were unsatisfactory. In addition, their study also determined that ECMO therapy might be contraindicated in patients aged 60 years and older [18]. Therefore, to reach a decision on the standard of care, more research needs to be done.

Pulmonary Embolism

ECMO therapy has also demonstrated better clinical outcomes with massive pulmonary embolism, which is fatal in patients because it can cause acute irreversible pulmonary and cardiac failure [19-20]. In 2007, a retrospective study was performed at the University of Michigan Medical Center for determining whether using ECMO therapy in massive pulmonary embolism patients improved their prognosis. The average duration of ECMO therapy utilization for survivors was 5.4 days, ranging from 5 hours to 12.5 days. The overall survival rate was $62 \%$ (13/21) when combined with anticoagulation or surgical embolectomy [19]. A prospective study conducted in 2012 similarly demonstrated an improved prognosis in 30-day survival rate of patients (70\%) [20].

Post-operative Cardiogenic Shock and Post-transplant Primary Graft Failure

Post-operative cardiogenic shock refers to post-cardiotomy cardiogenic shock, which is a rare and deadly complication of cardiac surgery [3]. A 2012 study with 517 patients determined that ECMO therapy given to 
post-cardiotomy cardiogenic shock patients still leads to a high morbidity and high mortality rate. Therefore, it becomes crucial to administer the treatment in patients based on their individual risk profiles rather than as a standard of care [21].

ECMO therapy is also used in primary graft failure secondary to heart transplantation, which is also associated with a high mortality [22-23]. In a previous retrospective study, ECMO-supported patients showed a good survival-to-discharge rate [24].

Bridge to ventricular assist device (VAD) Implantation or Heart Transplantation

A VAD is an implantable mechanical pump that helps pump blood from the ventricles to the rest of the body. It is used in patients of cardiac failure and as a bridging therapy for patients awaiting heart transplantation $[25]$.

ECMO therapy is used as a bridging therapy to heart transplantation or VAD implantation, or it can be used as supportive therapy to stabilize the patient till their prognosis becomes known [26-27]. In a previous prospective study, it was determined that ECMO is a valid method of supporting patients awaiting highurgency heart transplantation and can be used as a short-term bridge to surgery [27]. Despite this, as physicians, we still need more studies to address the relative and absolute contraindications of mechanical circulatory support [3].

Prevention of Right Ventricular Failure After LVAD Implantation

Once a patient has an implanted VAD, then it becomes important to allow time for the already compromised right ventricle to adjust to the increasing preload. By using ECMO therapy, right ventricular distention and failure can be avoided [3]. Studies performed in 2011 and 2012 have demonstrated that ECMO is an excellent supportive therapy for patients with recently implanted VAD. Improved patient prognosis was documented [28-29].

Pulmonary Hypertension

VA-ECMO therapy has become an important part of therapy for pulmonary hypertension complicated further by right ventricular failure, suboptimal medical therapy, or future lung transplantation [30]. During ECMO therapy, pulmonary vasodilators may be optimized for maximizing treatment effectiveness [30]. Pulmonary hypertension patients have high pulmonary vascular resistance ( $\geqslant 25 \mathrm{~mm} \mathrm{Hg}$ ), which can lead to right heart failure and eventually death without proper treatment [3]. Therefore, it becomes important to provide ECMO cannulation that can deliver the appropriate therapy, bypass the pulmonary vasculature, and decompress the right ventricle [3]. Femoral cannulation is avoided [3]. Studies have discovered that one option proven to work is having a drainage cannula in the internal jugular vein with a reinfusion cannula inserted into the subclavian artery [31]. An arteriovenous ECMO can be inserted between the main pulmonary artery and the left atrium after a sternotomy [32]. An oxygenated right-to-left shunt can be created for patients with pre-existing atrial defects while also decompressing the right ventricle [33-34].

\section{Uses in respiratory failure}

Acute Respiratory Distress Syndrome

ARDS is one of the most studied indications for ECMO therapy. ARDS is a life-threatening condition caused by capillary endothelial injury and diffuse alveolar damage, and leads to poor oxygenation and noncompliant lungs [35]. Volume and pressure-limited ventilation strategy is the only ventilation strategy proven to reduce ARDS mortality because positive-pressure ventilation may cause barotrauma [36-37]. Lowtidal volume can also cause further problems in ARDS patients like hypercapnia and respiratory acidosis. ECMO can help give the lungs rest and correct these problems [38]. Several studies have demonstrated the benefit of ECMO therapy in ARDS. One was the CESAR trial which determined that an ECMO-based management protocol would significantly improve survival without severe disability [39]. The CESAR trial was a multicentre randomized clinical trial (RCT). In contrast, the EOLIA 2018 trial (another RCT) determined that ARDS 60-day mortality was not significantly lower with ECMO therapy [5].

Hypercapnic Respiratory Failure

Hypercapnic respiratory failure (HRF) is defined as chronic respiratory failure characterized by elevated levels of carbon dioxide in the blood. HRF is mainly seen as a result of chronic obstructive pulmonary disease or long-standing obesity hypoventilation syndrome. Giving the patient treatment with invasive mechanical ventilation will lead to complications like dynamic hyperinflation and elevations in intrinsic positive end-expiratory pressure, ventilator-associated pneumonia, and impaired delivery of aerosolized medications [40-41]. Because of these potential complications, ECMO therapy has been found to be an excellent supportive therapy for HRF [3]. This has been confirmed with clinical trials, where ECMO therapy improved the prognosis of HRF patients [42]. 
ECMO therapy has been proven to provide appropriate (pulmonary and/or circulatory) support for patients waiting for lung transplantation [3]. Many transplantation surgeries develop primary graft failure, which is the first cause of early mortality after lung, and heart-lung transplantation [3]. The International Society for Heart-Lung Transplantation Registry determined a $24.7 \%$ and $27 \%$ mortality rate for lung and heart-lung transplantation, respectively. The underlying cause was primary graft dysfunction during the first 30 days after the operation [43]. Because of this, mechanical support therapy such as VA-ECMO is utilized. It has been determined that VA-ECMO can improve survival rates (82\%) of primary graft rejection patients [44-46].

\section{Use in cardiopulmonary resuscitation}

ECMO therapy has also been applied to cardiopulmonary resuscitation (CPR). In fact, studies performed on the effectiveness of ECMO plus CPR show improved short-term and long-term benefits compared to conventional CPR [47-48]. One 2008 study showed a significant difference in survival-to-discharge rate (hazard ratio [HR] 0.51, 95\% confidence interval [CI] 0.35-0.74, p-value<0.0001), 30-day survival (HR 0.47, 95\% CI 0.28-0.77, p-value=0.003), and one-year survival (HR 0.53, 95\% CI 0.33-0.83, p-value=0.006) favoring ECMO therapy with CPR over conventional CPR [47].

A second study in 2013 determined that the extracorporeal membrane oxygenation with cardiopulmonary resuscitation (E-CPR) patient group had better two-year survival with minimal neurological impairment than the conventional cardiopulmonary resuscitation (C-CPR) patient group [48]. The two-year survival with minimal neurological impairment was fourfold higher in the E-CPR group than that in the C-CPR group (20.0\% versus $5.0 \%, \mathrm{HR}=0.53,95 \% \mathrm{CI}=0.36-0.80$, $\mathrm{p}$-value $=0.002$ ) [48].

\section{Conclusions}

With the many uses of ECMO therapy, it becomes important for physicians both in and out of the hospital to familiarize themselves with the subject. This is a review article for those physicians regarding the background, the principle, the types, and the uses of ECMO therapy in different types of organ failure. Despite our current breadth of knowledge, more studies need to be done. We still need more data on ECMO therapy contraindications and complications, as well as its uses in high mortality conditions. Our hope is that more physicians will strive for larger prospective studies in order to address these unanswered questions.

\section{Additional Information \\ Disclosures}

Conflicts of interest: In compliance with the ICMJE uniform disclosure form, all authors declare the following: Payment/services info: All authors have declared that no financial support was received from any organization for the submitted work. Financial relationships: All authors have declared that they have no financial relationships at present or within the previous three years with any organizations that might have an interest in the submitted work. Other relationships: All authors have declared that there are no other relationships or activities that could appear to have influenced the submitted work.

\section{References}

1. Squiers JJ, Lima B, DiMaio JM: Contemporary extracorporeal membrane oxygenation therapy in adults: fundamental principles and systematic review of the evidence. J Thorac Cardiovasc Surg. 2016, 152:20-32. 10.1016/j.jtcvs.2016.02.067

2. Sauer CM, Yuh DD, Bonde P: Extracorporeal membrane oxygenation use has increased by $433 \%$ in adults in the United States from 2006 to 2011. ASAIO J. 2015, 61:31-36. 10.1097/MAT.0000000000000160

3. Abrams D, Combes A, Brodie D: Extracorporeal membrane oxygenation in cardiopulmonary disease in adults. J Am Coll Cardiol. 2014, 63:2769-2778. 10.1016/j.jacc.2014.03.046

4. Kulkarni T, Sharma NS, Diaz-Guzman E: Extracorporeal membrane oxygenation in adults: a practical guide for internists. Cleve Clin J Med. 2016, 83:373-384.

5. Combes A, Hajage D, Capellier G, et al.: Extracorporeal membrane oxygenation for severe acute respiratory distress syndrome. N Engl J Med. 2018, 24:1965-1975. 10.1056/NEJMoa1800385

6. Brodie D, Bacchetta M: Extracorporeal membrane oxygenation for ARDS in adults. N Engl J Med. 2011, 365:1905-1914. 10.1056/NEJMct1103720

7. Javidfar J, Brodie D, Wang D, et al.: Use of bicaval dual-lumen catheter for adult venovenous extracorporeal membrane oxygenation. Ann Thorac Surg. 2011, 91:1763-1768. 10.1016/j.athoracsur.2011.03.002

8. Wang D, Zhou X, Liu X, Sidor B, Lynch J, Zwischenberger JB: Wang-Zwische double lumen cannula-toward a percutaneous and ambulatory paracorporeal artificial lung. ASAIO J. 2008, 54:606-611. 10.1097/MAT.0b013e31818c69ab

9. Kosaraju A, Hai O: Cardiogenic Shock. StatPearls Publishing, Treasure Island, FL; 2019.

10. Asaumi Y, Yasuda S, Morii I, et al.: Favourable clinical outcome in patients with cardiogenic shock due to fulminant myocarditis supported by percutaneous extracorporeal membrane oxygenation. Eur Heart J. 2005, 26:2185-2192. 10.1093/eurheartj/ehi411

11. Fayssoil A, Nardi O, Orlikowski D, Combes A, Chastre J, Annane D: Percutaneous extracorporeal membrane 
oxygenation for cardiogenic shock due to acute fulminant myocarditis. Ann Thorac Surg. 2010, 89:614-616. 10.1016/j.athoracsur.2009.07.047

12. Pages ON, Aubert S, Combes A, et al.: Paracorporeal pulsatile biventricular assist device versus extracorporal membrane oxygenation-extracorporal life support in adult fulminant myocarditis. J Thorac Cardiovasc Surg. 2009, 137:194-197. 10.1016/j.jtcvs.2008.09.051

13. Richardson P, McKenna W, Bristow M, et al.: Report of the 1995 World Health Organization/International Society and Federation of Cardiology Task Force on the definition and classification of cardiomyopathies. Circulation. 1996, 93:841-842. 10.1161/01.CIR.93.5.841

14. Sheu JJ, Tsai TH, Lee FY, et al.: Early extracorporeal membrane oxygenator-assisted primary percutaneous coronary intervention improved 30-day clinical outcomes in patients with ST-segment elevation myocardial infarction complicated with profound cardiogenic shock. Crit Care Med. 2010, 38:1810-1817. 10.1097/CCM.0b013e3181e8acf7

15. Tsao NW, Shih CM, Yeh JS, et al.: Extracorporeal membrane oxygenation-assisted primary percutaneous coronary intervention may improve survival of patients with acute myocardial infarction complicated by profound cardiogenic shock. J Crit Care. 2012, 27:530-531. 10.1016/j.jcrc.2012.02.012

16. Bréchot N, Luyt CE, Schmidt M, et al.: Venoarterial extracorporeal membrane oxygenation support for refractory cardiovascular dysfunction during severe bacterial septic shock. Crit Care Med. 2013, 41:16161626. 10.1097/CCM.0b013e31828a2370

17. Riera J, Argudo E, Ruiz-Rodríguez JC, Ferrer R: Extracorporeal membrane oxygenation for adults with refractory septic shock. ASAIO J. 2018, 10.1097/MAT.0000000000000905

18. Huang CT, Tsai YJ, Tsai PR, Ko WJ: Extracorporeal membrane oxygenation resuscitation in adult patients with refractory septic shock. J Thorac Cardiovasc Surg. 2013, 146:1041-1046. 10.1016/j.jtcvs.2012.08.022

19. Maggio P, Hemmila M, Haft J, Bartlett R: Extracorporeal life support for massive pulmonary embolism . J Trauma. 2007, 62:570-576. 10.1097/TA.0b013e318031cd0c

20. Munakata R, Yamamoto T, Hosokawa Y, et al.: Massive pulmonary embolism requiring extracorporeal life support treated with catheter-based interventions. Int Heart J. 2012, 53:370-374. 10.1536/ihj.53.370

21. Rastan AJ, Dege A, Mohr M, et al.: Early and late outcomes of 517 consecutive adult patients treated with extracorporeal membrane oxygenation for refractory postcardiotomy cardiogenic shock. J Thorac Cardiovasc Surg. 2010, 139:302-311. 10.1016/j.jtcvs.2009.10.043

22. D'Alessandro C, Aubert S, Golmard JL, et al.: Extra-corporeal membrane oxygenation temporary support for early graft failure after cardiac transplantation. Eur J Cardiothorac Surg. 2010, 37:343-349. 10.1016/j.ejcts.2009.05.034

23. D'Alessandro C, Golmard JL, Barreda E, et al.: Predictive risk factors for primary graft failure requiring temporary extra-corporeal membrane oxygenation support after cardiac transplantation in adults.Eur. J Cardiothorac Surg. 2011, 40:962-969. 10.1016/j.ejcts.2011.01.064

24. Marasco SF, Vale M, Pellegrino V, et al.: Extracorporeal membrane oxygenation in primary graft failure after heart transplantation. Ann Thorac Surg. 2010, 90:1541-1546. 10.1016/j.athoracsur.2010.05.066

25. McMurray JJ, Adamopoulos S, Anker SD, et al.: ESC guidelines for the diagnosis and treatment of acute and chronic heart failure 2012: The Task Force for the Diagnosis and Treatment of Acute and Chronic Heart Failure 2012 of the European Society of Cardiology. Developed in collaboration with the Heart Failure Association (HFA) of the ESC. Eur J Heart Fail. 2012, 14:803-869. 10.1093/eurjhf/hfs105

26. Chung JC, Tsai PR, Chou NK, Chi NH, Wang SS, Ko WJ: Extracorporeal membrane oxygenation bridge to adult heart transplantation. Clin Transplant. 2010, 24:375-380. 10.1111/j.1399-0012.2009.01084.x

27. Barth E, Durand M, Heylbroeck C, et al.: Extracorporeal life support as a bridge to high-urgency heart transplantation. Clin Transplant. 2012, 26:484-488. 10.1111/j.1399-0012.2011.01525.x

28. Lebreton G, Nicolescu M, Léger P, Leprince P: Implantation of left ventricular support under extracorporeal membrane oxygenation. Eur J Cardiothorac Surg. 2011, 40:165-167. 10.1016/j.ejcts.2011.06.012

29. Takayama H, Naka Y, Kodali SK, et al.: A novel approach to percutaneous right-ventricular mechanical support. Eur J Cardiothorac Surg. 2012, 41:423-426. 10.1016/j.ejcts.2011.05.041

30. Abrams DC, Brodie D, Rosenzweig EB, Burkart KM, Agerstrand CL, Bacchetta MD: Upper-body extracorporeal membrane oxygenation as a strategy in decompensated pulmonary arterial hypertension. Pulm Circ. 2013, 3:432-435. 10.4103/2045-8932.113178

31. Javidfar J, Brodie D, Costa J, et al.: Subclavian artery cannulation for venoarterial extracorporeal membrane oxygenation. ASAIO J. 2012, 58:494-498. 10.1097/MAT.0b013e318268ea15

32. Strueber M, Hoeper MM, Fischer S, et al.: Bridge to thoracic organ transplantation in patients with pulmonary arterial hypertension using a pumpless lung assist device. Am J Transplant. 2009, 9:853-857. 10.1111/j.1600-6143.2009.02549.x

33. Javidfar J, Brodie D, Sonett J, Bacchetta M: Venovenous extracorporeal membrane oxygenation using a single cannula in patients with pulmonary hypertension and atrial septal defects. J Thorac Cardiovasc Surg. 2012, 143:982-984. 10.1016/j.jtcvs.2011.10.061

34. Camboni D, Akay B, Sassalos P, et al.: Use of venovenous extracorporeal membrane oxygenation and an atrial septostomy for pulmonary and right ventricular failure. Ann Thorac Surg. 2011, 91:144-149. 10.1016/j.athoracsur.2010.07.036

35. Peniston Feliciano HL, Mahapatra S: Acute Respiratory Distress Syndrome. StatPearls Publishing, Treasure Island, FL; 2019.

36. American Thoracic Society, the European Society of Intensive Care Medicine, and the Societé de Réanimation de Langue Française: International consensus conferences in intensive care medicine: Ventilator-associated Lung Injury in ARDS. This official conference report was cosponsored by the American Thoracic Society, The European Society of Intensive Care Medicine, and The Societé de Réanimation de Langue Française, and was approved by the ATS Board of Directors, July 1999. Am J Respir Crit Care Med. 1999, 160:2118-2124. 10.1164/ajrccm.160.6.ats16060

37. Brower RG, Matthay MA, Morris A, Schoenfeld D, Thompson BT, Wheeler A: Ventilation with lower tidal volumes as compared with traditional tidal volumes for acute lung injury and the acute respiratory distress syndrome. N Engl J Med. 2000, 342:1301-1308. 10.1056/NEJM200005043421801 
38. Combes A, Bréchot N, Luyt CE, Schmidt M: What is the niche for extracorporeal membrane oxygenation in severe acute respiratory distress syndrome?. Curr Opin Crit Care. 2012, 18:527-532.

10.1097/MCC.0b013e328357f090

39. Peek GJ, Mugford M, Tiruvoipati R, et al.: Efficacy and economic assessment of conventional ventilatory support versus extracorporeal membrane oxygenation for severe adult respiratory failure (CESAR): a multicentre randomised controlled trial. Lancet. 2009, 17:1351-1363. 10.1016/S0140-6736(09)61069-2

40. Ai-Ping C, Lee KH, Lim TK: In-hospital and 5-year mortality of patients treated in the ICU for acute exacerbation of COPD: a retrospective study. Chest. 2005, 128:518-524. 10.1378/chest.128.2.518

41. Bekaert M, Timsit JF, Vansteelandt S, et al.: Attributable mortality of ventilator-associated pneumonia: a reappraisal using causal analysis. Am J Respir Crit Care Med. 2011, 184:1133-1139. 10.1164/rccm.2011050867OC

42. Conrad SA, Zwischenberger JB, Grier LR, Alpard SK, Bidani A: Total extracorporeal arteriovenous carbon dioxide removal in acute respiratory failure: a phase I clinical study. Intensive Care Med. 2001, 27:13401351. doi.org/10.1007/s001340100993

43. Yusen RD, Christie JD, Edwards LB, et al.: The Registry of the International Society for Heart and Lung Transplantation: Thirtieth Adult Lung and Heart-Lung Transplant Report--2013; focus theme: age. J Heart Lung Transplant. 2013, 32:965-978. 10.1016/j.healun.2013.08.007

44. Hartwig MG, Walczak R, Lin SS, Davis RD: Improved survival but marginal allograft function in patients treated with extracorporeal membrane oxygenation after lung transplantation. Ann Thorac Surg. 2012, 93:366-371. 10.1016/j.athoracsur.2011.05.017

45. Mihaljevic T, Jarrett CM, Gonzalez-Stawinski G, et al.: Mechanical circulatory support after heart transplantation. Eur J Cardiothorac Surg. 2012, 41:200-206. 10.1016/j.ejcts.2011.04.017

46. Lima EB, Cunha CR, Barzilai VS, et al.: Experience of ECMO in primary graft dysfunction after orthotopic heart transplantation. Arq Bras Cardiol. 2015, 105:285-291. 10.5935/abc.20150082

47. Chen YS, Lin JW, Yu HY, et al.: Cardiopulmonary resuscitation with assisted extracorporeal life-support versus conventional cardiopulmonary resuscitation in adults with in-hospital cardiac arrest: an observational study and propensity analysis. Lancet. 2008, 372:554-561. 10.1016/S0140-6736(08)60958-7

48. Shin TG, Jo IJ, Sim MS, et al.: Two-year survival and neurological outcome of in-hospital cardiac arrest patients rescued by extracorporeal cardiopulmonary resuscitation. Int J Cardiol. 2013, 168:3424-3430. 10.1016/j.ijcard.2013.04.183 